\title{
Determinants of Bicycle-On-Bus Boardings: A Case Study of the Greater Cleveland RTA
}

\author{
Bradley J. Flamm, Temple University
}

\begin{abstract}
Transit agencies around the country have made significant investments since the late 1990s to provide improved service to cyclist-transit users (CTUs), that is, transit riders who bring bicycles with them by using bicycle racks installed on buses. Use of these bus bicycle racks appears to vary significantly from transit system to transit system. It is unclear, however, what specific factors contribute most to bicycle-onbus boardings (BoBBs). Using multi-variate regression analysis and a detailed data set of 2008-2011 BoBBs for Northeast Ohio's Greater Cleveland Regional Transit Authority (GCRTA), this study compared daily BoBBs to general ridership (measured by unlinked passenger trips) in light of key weather, transit service, and travel cost variables. Rates of BoBBs rose during the study's time period and were strongly associated with weather conditions, though even in wet and cold weather, dozens of transit users traveled with their bicycles. To a lesser extent, BoBBs are also associated with transit service levels and travel costs.
\end{abstract}

\section{Introduction}

Beginning in the 1990s, transit system managers, planners, bicycling and environmental advocates, and funders have embraced the goal of coordinating bicycling and transit service. Public transit systems throughout the United States have made large capital investments (often with generous federal financial assistance) to place bicycle racks on buses, install bicycle parking and services facilities at transit sta- 
tions, and make policy changes to permit bicycles on trains and streetcars. U.S. transit systems now have bicycle racks installed on a majority of buses-72 percent, according to the 2011 edition of the American Public Transit Association Fact Book (APTA 2011). Seven of the eight largest North American transit systems have installed bicycle racks on 100 percent of transit buses (New York City Transit is the exception, with no bus bicycle racks installed). Policies regarding bicycle access to rail cars vary from agency to agency, with frequent prohibitions during peak commuting hours, but a growing number of transit systems are finding ways to accommodate bicycles on trains and streetcars.

The principal goals of such efforts are to increase transit use and cycling trips and give travelers more choices and greater flexibility. Environmental, health, and traffic congestion-mitigation benefits are expected as a result. By welcoming cyclistsallowing them to become what Krizek et al. (2011) term cycle-transit users (CTUs) and Hagelin (2005) identifies as bike-on-bus users-transit agencies create opportunities for more people to conveniently use buses, trains, and trolleys.

In some cases, this coordination between transit and cycling is so successful that capacity limits are reached, with racks on transit vehicles unable to accommodate additional demand for bicycles due to space constraints. Transit agencies in several states, particularly where there are high levels of recreational bicycling, have had to address this challenge in recent years (Krizek and Stonebraker 2010). Most transit agencies, however, are like Cleveland, Ohio's Greater Cleveland Regional Transit Authority (GCRTA), which has bicycle racks installed on every bus but no significant capacity problems. Transit riders who want to travel with their bicycles can make that decision without worrying that there will be no room for them on their bus or train.

The presence of bus bicycle racks and supportive transit-bicycle policies, however, is only one factor in a transit user's decision to travel with a bicycle. Other factors come into play as travel behavior choices are made, but there is little empirical evidence as to what those factors are. How do weather conditions, travel costs, transit service levels, employment, and other variables affect the number of daily bicycleson-bus boardings (BoBBs) for a major public transit agency like GCRTA? (GCRTA is the 34th largest U.S. transit agency, as measured by annual unlinked passenger miles [APTA 2011], with more than 350 buses in service on a typical weekday covering 35,000 vehicle miles and serving tens of thousands of riders.) Do such factors affect transit users without bicycles in the same ways they affect CTUs?

A detailed 2008-2011 dataset of more than 160,000 BoBBs maintained by Northeast Ohio's GCRTA gives us an opportunity to study these factors in more detail. 
This question can be asked: On a typical day in the operations of a large public transit system, what determines the number of bus riders who decide to travel with their bicycles? The opportunity is there for transit customers who would like to do so, since a bicycle rack with the capacity for two bicycles is installed on every revenue bus. Yet, some days, fewer than two dozen CTUs place their bikes on a bus bicycle rack, and on other days 300 or more will do so. What factors influence the highly variable number of BoBBs observed on GCRTA's motor bus network in recent years?

The analysis of GCRTA's data set of BoBBs, reviewed in conjunction with data from other sources, permits a detailed assessment of these questions. To take a comprehensive approach, this paper addresses three key research questions related to GCRTA's operations:

- What are the determinants of bicycle-on-bus boardings?

- What are the determinants of general transit ridership?

- How do the determinants differ for the two categories of transit users?

The remainder of this paper is organized as follows: First is a discussion of the history of bicycle-transit coordination in the United States, with an emphasis on GCRTA's bicycles and transit investments and policies. Second, the analytical methodologies and data sets used are described, followed by descriptions of the results of the quantitative analysis. Finally, the paper concludes with a discussion of some implications of the findings and suggested future analytical steps.

\section{Background}

Cycle-transit users have been the subject of several studies in the past decade, each of which highlights a clear trend: transit agencies are making important changes to their vehicles, facilities, and policies to accommodate transit riders who are also cyclists (Hagelin 2005; Pucher and Buehler 2009; Schneider 2005). Schneider's detailed and comprehensive report on behalf of the Transit Cooperative Research Program of the Transportation Research Board (2005) categorized and documented a variety of capital investments and policy changes transit agencies in North America have adopted. These include services and amenities for both CTUs who leave their bicycles at transit stops or stations and CTUs who travel with them on transit vehicles. Bicycle racks on buses, bicycle racks and lockers at transit stops and stations, bicycle kiosks (usually at larger transit stations where bicycles are for sale and repairs are made), and policies granting bicycle access to rail vehicles are the most common coordination methods transit agencies have implemented. 
Krizek and Stonebraker $(2010,2011)$ and Bachand-Marleau et al. (2011) have examined this "marriage" of transit and bicycling and identified opportunities for improving coordination to benefit both transit riders and cyclists. Paradoxically, the transit agencies that experience the most significant difficulties are those in which the integration of the modes has been most successful, where demand sometimes outstrips the capacity of transit vehicles to accommodate bicycles. Krizek and Stonebraker (2010), for example, report that transit providers in California (Caltrain), Colorado (Boulder County), and Washington (Puget Sound Regional Council) have been motivated by CTU capacity limitations to develop programs to improve the quality of transit service while reducing incidences of CTU overcapacity.

Missing from most of these studies, however, are consistently-administered counts of BoBBs on transit agency's vehicle fleets. The Philadelphia region's largest transit service provider, SEPTA, for example, conducts counts infrequently, relying on vehicle operator manual tallies. The resulting data are not considered highly reliable nor do they provide sufficient detail to identify trends and variations in CTU behavior.

GCRTA, however, is an exception. Beginning in 2000, bus bicycle racks were regularly installed on new revenue buses, with complete coverage of the transit agency's revenue bus fleet accomplished within a few years' time. Collection of data on CTUs began in 2005 with a somewhat cumbersome system that required bus operators to call dispatchers each time a transit user placed a bicycle in a rack. In 2007, with the installation of improved farebox technology, the system was simplified with on-board computers. At first, and through 2010, only the date, time, and bus route number or name were recorded; beginning in 2011, location data have also been collected.

\section{Methodology and Data Analyzed}

To answer this project's research questions, analytical methods were developed that reflect a straightforward conceptual model, the availability of detailed data for the time period January 1, 2008, to December 31, 2011, and statistical analysis conducted using SPSS software (version 19).

\section{Conceptual Model}

The conceptual model used in this project (Figure 1) incorporates five categories of variables that have been identified as useful predictors of transit ridership in previous studies. 
- Travel costs, because of their importance in consumer economics theory, have consistently been included in analyses of transit ridership (Lane 2012; Taylor et al. 2009; Chen et al. 2011). Travelers have choices to make with clear time and money implications, so they weigh the comparative costs and benefits of transit, driving, bicycling and using other travel modes.

- Employment, measured in this study by the number of people with paid jobs in the region, reflects demand for travel and is important for a study of public transportation, a mode with a high proportion of commute-related trips.

- Transit service levels are included because they reflect the opportunities travelers have to take public transportation.

- Weather variables, though they have only infrequently been included in studies of transit ridership (Stover and McCormack 2012), are logical to include in a study examining BoBBs, given the discomfort of riding in very cold or hot, very wet, or snowy weather.

- Bicycle ridership is directly related to bicycle-on-bus boardings: the more cyclists on the road, the more likely that BoBB numbers will rise too.

\section{Explanatory Variables}

\section{Travel Costs}

- GCRTA Bus Fare

- Price of gasoline

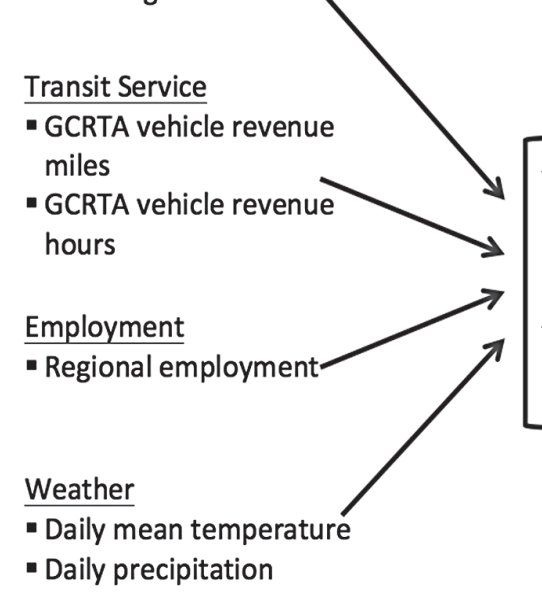

Outcome Variables

General Ridership

- Daily GCRTA unlinked passenger trips

Cycle-Transit Users Ridership

- Daily GCRTA bicycle-on-bus boardings

Figure 1. Conceptual model relating explanatory to outcome variables 


\section{Data}

The geographic area of analysis in this study is the GCRTA service area, located primarily in Cuyahoga County, Ohio, including the city of Cleveland and its older suburbs. Each of the 1,461 records in the data set represents a calendar day in 2008, 2009, 2010, and 2011, with variables related to daily GCRTA ridership, fares, and service levels, weather conditions, regional employment, the cost of gasoline, and bicycle ridership. Consequently, the unit of analysis for this data set is the calendar day. Several data preparation steps, briefly described below, were required to develop the final database used for the analysis.

Bicycle-on-bus boarding data provided by GCRTA included more than 160,000 records for the four-year time period of this study, each representing a single occurrence of a transit rider placing a bicycle in a bus bicycle rack. These records were summed to obtain daily BoBBs.

Unlinked passenger trips (UPTs), vehicle revenue miles (VRMs), and vehicle revenue hours (VRHs) for GCRTA motor buses are reported on a monthly basis by the National Transit Database program of the Federal Transit Administration. Monthly data are not reported separately for work days versus non-work days (Saturdays, Sundays, and federal holidays), but the distinction is made in annual statistics, and these values were used to create workday/non-workday ridership ratios. These ratios were applied to UPT, VRM, and VRH data for each month and the results used to estimate daily ridership and service levels.

The standard, on-board fare for an unlinked trip represents the cost of riding GCRTA buses. This fare changed twice during the time period of this study, starting at $\$ 1.75$ on January 1,2008 , rising to $\$ 2.00$ in October 2008 , and then increasing to $\$ 2.25$ in September 2009.

Employment data are based on monthly figures for the Cleveland-Elyria-Mentor Metropolitan Statistical Area, obtained from the Bureau of Labor Statistics of the U.S. Department of Labor.

Weather data were obtained from the National Weather Service. Temperature, humidity, wind speed and direction, precipitation, air pressure, and dew point data are reported on a daily basis. Only mean daily temperature and precipitation data, however, were used for this analysis.

Weekly gasoline prices for Cleveland (average for all grades) were obtained from the Energy Information Administration of the U.S. Department of Energy. Weekly prices were assigned to each day of the week for purposes of this analysis. 
Finally, bicycle ridership data were obtained from two sources: the U.S. Census Bureau's American Community Survey and the Northeast Ohio Areawide Coordinating Agency (NOACA), the Metropolitan Planning Organization for the Cleveland metropolitan area.

\section{Findings}

The time period of this analysis was one of significant economic challenges at the regional and national levels that seriously impacted GCRTA's ability to provide service to its riders. While managerial decisions made prior to the economic downturn of 2008 created efficiencies that softened the blows of the recession (Freilich 2011), GCRTA was, nevertheless, obliged to raise fares and make significant service cuts. The standard bus fare rose 29 percent, from $\$ 1.75$ to $\$ 2.25$, between January 1 , 2008 , and the fall of 2009 , then remained at $\$ 2.25$ through the end of 2011 . Vehicle revenue miles of service and vehicle revenue hours of service were 32 percent and 30 percent lower, respectively, in 2011 than they were in 2008.

Ridership, as measured in unlinked passenger trips (UPTs), not surprisingly dropped significantly as these fare increases and service cuts were implemented. From 2008 levels of ridership of 134,000 per day, UPTs fell 24 percent, to about 102,000 per day in 2011.

The recession contributed to GCRTA's difficulties in other ways. Regional employment was down 2.6 percent from 2008 to 2011, from an average of 1,026,222 employed workers to an average of 999,611 , reducing demand for daily commute trips. Gasoline prices showed great variability, creating uncertainty and significant out-of-pocket expenses. The lowest price (in current dollars) during the period 2008 to 2011 of $\$ 1.60$ for a gallon of gasoline was less than half of the highest average pump price of $\$ 4.16$ per gallon. Annual gasoline price averages were $\$ 3.23$ per gallon in 2008, \$2.34 in 2009, \$2.76 in 2010, and \$3.50 in 2011.

The relationship between ridership and transit service levels was very close during 2008-2011, as indicated by a Pearson correlation coefficient (PCC) of 0.908 . While more variability in UPTs is evident in Figure 2 than in vehicle revenue miles, the overall trend of higher values earlier in the period of analysis and lower values later on is quite close. Economic conditions, however, were less directly related to ridership: unlinked passenger trips and employment have a relatively weak PCC of only 0.200 , indicating that ridership and employment did not display similar patterns of high and low values. 


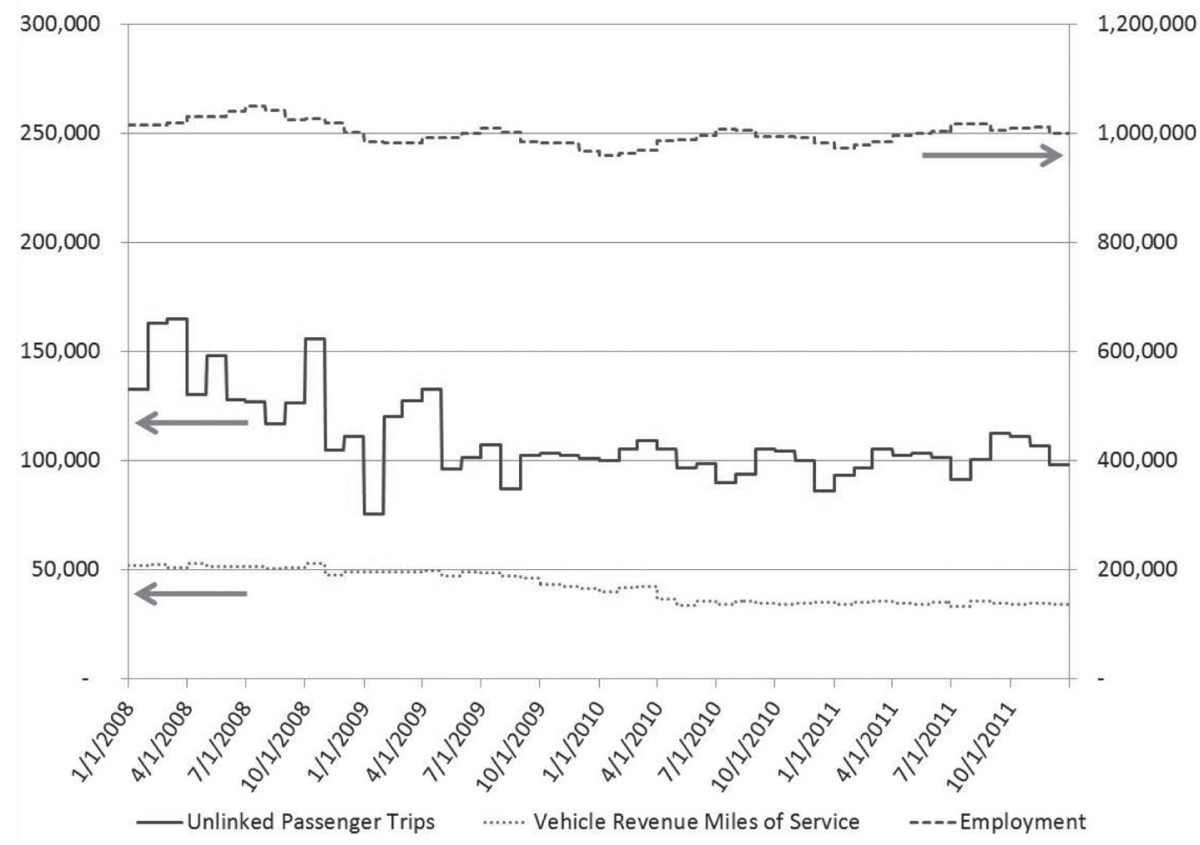

\section{Figure 2. GCRTA daily ridership (unlinked passenger trips) and regional employment and transit service levels, 2008 to 2011}

The relationships between UPTs and both gasoline prices and bus fares reflect standard economic theory: that is, higher gasoline prices are positively associated with UPTs (as it becomes more expensive to drive, taking transit becomes more attractive to commuters), and higher bus fares are negatively associated with transit ridership (as riding transit becomes more expensive, it is less attractive to commuters) (Figure 3). However, while the direction of the association of these variables is as expected, the strength of these associations is relatively low: UPTs and bus fare are associated with a PCC of -0.289 and UPTs and gasoline prices with a PCC of only 0.082 , suggesting that bus ridership during this time period in northeast Ohio was not particularly sensitive to fares or to the cost of gasoline.

The drop in ridership from 2008 to 2011 was more pronounced on work days, with a 24.9 percent decrease, than on non-work days where the decline was "only" 18.1 percent (Table 1). BoBBs also declined over the same period of time, though, significantly, not to the same degree, dropping 10.5 percent from 2008 to 2011. In fact, the difference in rates of decrease between general ridership and CTUs reflects an 


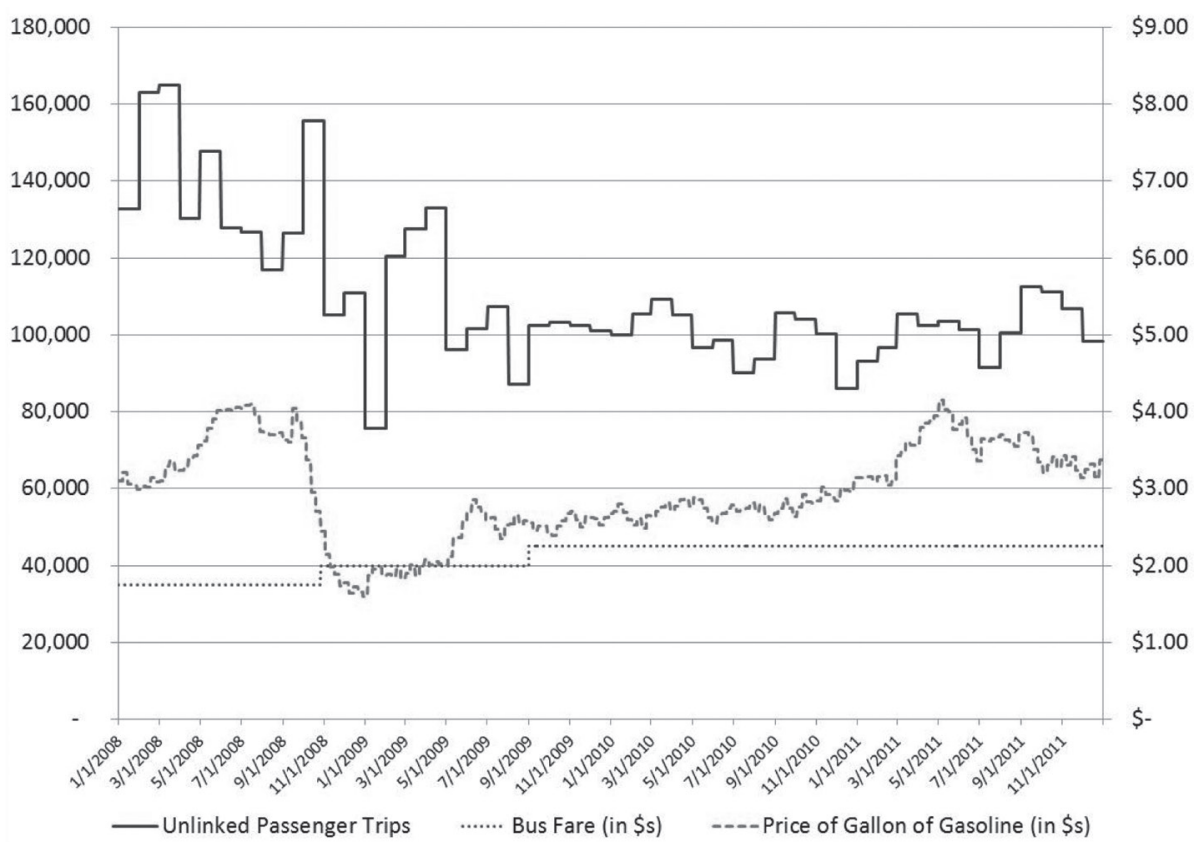

Figure 3. GCRTA daily ridership (unlinked passenger trips) and fare and gasoline prices, 2008 to 2011

increase in BoBB utilization when measured on a per 1,000 UPT basis (from 0.92 to $1.09 \mathrm{BoBBs} / 1,000$ UPTs). When examined separately, the increase in the rate of BoBBs is slightly more pronounced on work days than on non-work days (a $17.3 \%$ increase compared to $16.9 \%$ ), though the overall utilization is higher on non-work days than on work days, 1.83 compared to $0.98 \mathrm{BoBBs} / 1,000$ UPTs.

The number of transit users boarding GCRTA buses with bicycles reflects seasonal patterns: BoBBs are at their lowest levels in December, January, and February, with a daily average of 48. In the summer months (June, July, and August) the average rises to 165 daily BoBBs. Utilization also varies significantly by bus route. Two routes each accounted for 7 percent of total BoBBs (an average of 6-7 BoBBs per day) and 12 routes accounted for half of all BoBBs. Just 36 routes averaged one or more BoBBs per day, with dozens more in the less-than-one-BoBB-per-day category. 
Table 1. GCRTA Ridership and BoBBs, 2008-2011

\begin{tabular}{|c|c|c|c|}
\hline & BoBBs & UPTs & BoBBs/1,000 UPTs \\
\hline \multicolumn{4}{|l|}{ Non-Work Days } \\
\hline 2008 & 9,185 & $5,880,700$ & 1.56 \\
\hline 2009 & 8,621 & $5,675,931$ & 1.52 \\
\hline 2010 & 7,803 & $4,735,601$ & 1.65 \\
\hline 2011 & 8,755 & $4,794,631$ & 1.83 \\
\hline Change 2008-11 & $-4.7 \%$ & $-18.5 \%$ & $16.9 \%$ \\
\hline \multicolumn{4}{|l|}{ Work Days } \\
\hline 2008 & 36,170 & $43,167,714$ & 0.84 \\
\hline 2009 & 30,385 & $32,520,479$ & 0.93 \\
\hline 2010 & 30,298 & $31,580,559$ & 0.96 \\
\hline 2011 & 31,858 & $32,404,132$ & 0.98 \\
\hline Change 2008-11 & $-11.9 \%$ & $-24.9 \%$ & $17.3 \%$ \\
\hline \multicolumn{4}{|l|}{ All Days } \\
\hline 2008 & 45,355 & $49,048,414$ & 0.92 \\
\hline 2009 & 39,006 & $38,196,410$ & 1.02 \\
\hline 2010 & 38,101 & $36,316,160$ & 1.05 \\
\hline 2011 & 40,613 & $37,198,763$ & 1.09 \\
\hline Change 2008-11 & $-10.5 \%$ & $-24.2 \%$ & $18.1 \%$ \\
\hline
\end{tabular}

\section{Multi-Variate Regression Analysis}

Prior to running the regression models, the two outcome variables and eight candidate explanatory variables were examined for accuracy of data, missing values, and fit between their distributions and the assumptions of multivariate analysis. Descriptive statistics for these variables are found in Table 2.

Four problems required resolution before running the regressions. First, the inclusion of both VRMs and VRHs contributed to multi-collinearity in the models. The PCC between the two variables was so high (0.99) that the inclusion of both would have been redundant, so VRHs were dropped from the final version of the analysis.

Second, 17 multi-variate outliers (assessed using Mahalanobis distance scores assessed at the $\mathrm{p}<.001$ level) were identified, all for days with very high levels of precipitation. To resolve this issue, the precipitation data were transformed into a dummy variable in which days with no precipitation or very little precipitation (less than 0.1 inches) 
Table 2. Descriptive Statistics for Outcome and Explanatory Variables, 2008-2011

\begin{tabular}{|c|c|c|c|c|}
\hline & Minimum & Maximum & Mean & Std. Dev. \\
\hline \multicolumn{5}{|l|}{ Outcome Variables } \\
\hline Bicycles-on-bus boardings (daily BoBBs) & 0 & 302 & 111.6 & 62.9 \\
\hline Unlinked passenger trips (daily UPTs) & 35,752 & 212,851 & $110,034.1$ & $47,792.9$ \\
\hline \multicolumn{5}{|l|}{ Explanatory Variables } \\
\hline Mean temperature $\left({ }^{\circ} \mathrm{F}\right)$ & -5 & 88 & 51.8 & 18.8 \\
\hline Precipitation (dummy variable, $1>=0.10 \mathrm{in}$.) & 0 & 1 & 0.27 & 0.44 \\
\hline Regional employment $(1,000$ s) & 958.6 & $1,050.3$ & $1,000.3$ & 20.6 \\
\hline Standard bus fare (cents) & 175 & 225 & 209.5 & 20.1 \\
\hline Price of gallon of gasoline (cents) & 159.8 & 415.7 & 296.0 & 61.7 \\
\hline Vehicle revenue miles of service ( $100 \mathrm{~s}$ of mi) & 195.0 & 628.7 & 423.1 & 144.7 \\
\hline Vehicle revenue hours of service & 1,629 & 5,264 & 3,602 & $1,233.0$ \\
\hline
\end{tabular}

were coded " 0 " and other days coded "1." A total of 392 days-26.8 percent of the four-year period-were identified as having had significant precipitation.

Third, the difference in minimum and maximum values for regional employment ( $2.6 \%$ during the study's time-period) demonstrated too little variation to have a significant impact on the results of the regression models. Consequently, this variable was removed from the analysis.

Finally, the bicycle ridership data from the American Community Survey and from NOACA proved to be insufficiently detailed for use in the model: estimated numbers of bicyclists were available only on an annual basis and with high margins of error. Therefore, this variable too could not be included in the final analytical model (see Figure 4).

With data problems resolved, two multi-variate regression models to examine the factors hypothesized to affect both BoBBs and UPTs were finalized. The results of these analyses are shown in Tables 3 and 4. Unstandardized coefficients with their standard errors, standardized coefficients (beta), t-statistic and p-values are displayed, along with overall model fit statistics ( $R^{2}$ and $F$ values). Both models proved to be statistically significant, as were all variables. The models' explanatory powers were high, with $\mathrm{R}^{2}$ values indicating that $67.4 \%$ of the variability in daily BoBBs was accounted for by the first model and $88.5 \%$ of the variation in daily number of UPTs was accounted for in the second model. 


\section{Explanatory Variables}

Travel Costs

- GCRTA Bus Fare (in cents)

- Price of gasoline (in cents)

Transit Service

- GCRTA vehicle revenue miles (in 100s)

- GCRTA vehicle revenue hours

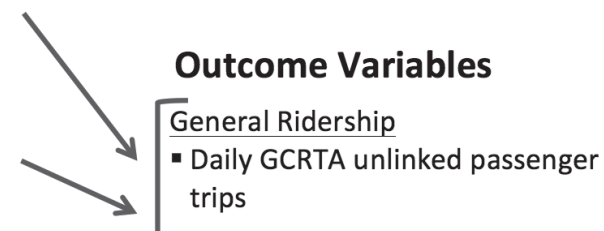

\section{Employment}

- Regional employment

Weather

- Daily mean temperature (in Fahrenheit degrees)

- Daily precipitation (dummy variable, $1=0.1$

Cycle-Transit Users Ridership

- Daily GCRTA bicycle-on-bus boardings inches or more)

NOTE: Variables identified in light grey text not included in final regression models.

\section{Figure 4. Analytical model relating explanatory to outcome variables}

Table 3. Model 1, Outcome Variable BoBBs, GCRTA, 2008-2011

\begin{tabular}{|l|c|c|c|c|c|}
\hline \multirow{2}{*}{\multicolumn{1}{|c|}{ Variable }} & \multicolumn{2}{|c|}{ Unstd. Coeffs. } & \multirow{2}{*}{$\begin{array}{c}\text { Std. } \\
\text { Coeff. }\end{array}$} & \multirow{2}{*}{$t$} & \multirow{2}{*}{ Sig. } \\
\cline { 2 - 5 } & $B$ & Std. Error & Beta & & \\
\hline Constant & -197.38 & 14.66 & & -13.47 & 0.000 \\
\hline Mean temperature $\left({ }^{\circ} \mathrm{F}\right)$ & 2.21 & 0.05 & 0.66 & 41.69 & 0.000 \\
\hline Precipitation (dummy variable, $1>=0.10 \mathrm{in}$.) & -22.06 & 2.13 & -0.16 & -10.34 & 0.000 \\
\hline Standard bus fare (cents) & 0.31 & 0.05 & 0.10 & 5.71 & 0.000 \\
\hline Price of gallon of gasoline (cents) & 0.19 & 0.02 & 0.18 & 11.35 & 0.001 \\
\hline Vehicle revenue miles of service (100s of $\mathrm{mi})$ & 0.19 & 0.01 & 0.44 & 25.78 & 0.000 \\
\hline
\end{tabular}

$R$ Square $=0.674, F=601.355, d f=5$, Sig. $=.000$

Weather proved to be the most important variable in predicting the number of daily BoBBs: every increase of $1^{\circ} \mathrm{F}$ in the mean daily temperature saw an average 
of 2.21 more BoBBs, and the occurrence of significant levels of precipitation was associated with an average of 22.06 fewer. With a quarter of the year in Greater Cleveland rainy or snowy and a difference of $60^{\circ}$ or more between average daily temperatures in the winter and in the summer, these factors can make very large differences.

Transit service levels, bus fare, and the cost of gasoline also proved to be statistically significant predictors of BoBBs. VRMs and gasoline prices both showed the expected relationship: as they increased, so, too, did BoBBs. Bus fare association with bicycle-on-bus boardings, however, was unexpected: even though the cost of riding the bus rose twice during the time period of this analysis, so, too, did BoBBs. There is no logical reason to believe that more CTUs are taking their bicycles with them on the bus because bus fares have risen. It is likely that transit users, whether traveling with or without a bicycle, are simply not sensitive to the cost of travel when fares rise only modestly, as they did during the time period of this study.

Table 4. Model 2, Outcome Variable UPTs, GCRTA, 2008-2011

\begin{tabular}{|l|c|c|c|c|c|}
\hline \multirow{2}{*}{ Variable } & \multicolumn{2}{|c|}{ Unstd. Coeffs. } & Std. Coeff. & \multirow{2}{*}{$t$} & \multirow{2}{*}{ Sig. } \\
\cline { 2 - 5 } & $B$ & Std. Error & Beta & & \\
\hline Constant & $-168,150.32$ & $6,607.39$ & & -25.45 & 0.000 \\
\hline Mean temperature $\left({ }^{\circ} \mathrm{F}\right)$ & -159.75 & 23.96 & -0.06 & -6.67 & 0.000 \\
\hline $\begin{array}{l}\text { Precipitation (dummy variable, } \\
1>=0.10 \text { in.) }\end{array}$ & $2,021.04$ & 961.66 & 0.02 & 2.10 & 0.036 \\
\hline Standard bus fare (cents) & 445.41 & 24.06 & 0.19 & 18.51 & 0.000 \\
\hline Price of gallon of gasoline (cents) & 174.32 & 7.47 & 0.23 & 23.32 & 0.000 \\
\hline $\begin{array}{l}\text { Vehicle revenue miles of service } \\
\text { (100s of mi) }\end{array}$ & 333.35 & 3.33 & 1.01 & 99.96 & 0.000 \\
\hline
\end{tabular}

$R$ Square $=0.885, F=2,241.615, d f=5$, Sig. $=.000$

In the second model that assessed general bus ridership as measured by unlinked passenger trips, levels of transit service proved to be far and away the most important determinant. For every increase of 100 miles of vehicle revenue service (an average day for GCRTA in 2011 saw almost 35,000 VRM), an additional 333 UPTs were observed. No other factor came close to being as important, the price of gasoline being a distant second in relative importance; as gasoline prices rose, so, too, did UPTs, but only in relatively small amount. As was the case with bicycle-onbus boardings, bus fare association with UPTs was positive, contrary to theoretical expectations, suggesting that, at least in difficult economic times, a simplistic rela- 
tionship between demand (for travel via transit) and price (the cost of a bus fare) does not reflect real-world conditions. Interestingly, precipitation was associated with an increase of 2,021 UPTs (about 2\% of a typical day's UPTs), and each rise in temperature of $1^{\circ} \mathrm{F}$ was associated with a drop in UPTs of 160 . The direction of the association between weather variables and UPTs (the opposite of their associations with BoBBs) may simply be a reflection of the reduction in the number of high school and college students using public transit during the warmer, drier summer months.

Table 5 summarizes the results of these analyses.

Table 5. Summary of Effects of Explanatory Variables Associated with BoBBs and UPTs, GCRTA, 2008-2011

\begin{tabular}{|l|c|c|}
\hline & BoBBs & UPTs \\
\hline Mean temperature $\left({ }^{\circ} \mathrm{F}\right)$ & $(+)$ Large positive & $(-)$ Very small negative \\
\hline Precipitation (dummy variable, $1>=0.10$ in.) & $(-)$ Small negative & $(+)$ Very small positive \\
\hline Standard bus fare (cents) & $(+)$ Small positive & $(+)$ Small positive \\
\hline Price of gallon of gasoline (cents) & $(+)$ Small positive & $(+)$ Small positive \\
\hline Vehicle revenue miles of service (100s of miles) & $(+)$ Medium positive & $(+)$ Large positive \\
\hline $\begin{array}{l}\text { Percentage of outcome variable variation } \\
\text { explained by model }\end{array}$ & $67.4 \%$ & $88.5 \%$ \\
\hline
\end{tabular}

Note: Large effects are $67 \%$ or more of the largest standardized coefficient (beta) value; medium effects are $33 \%$ up to $67 \%$ of the largest standardized coefficient; and small effects are less than $33 \%$.

\section{Discussion}

Bicycle-friendly policies implemented by public transit agencies have successfully expanded access to transit to riders who combine their travel with bicycling. Many transit users ride bicycles to transit stops and stations and leave their bicycles there, but others prefer or need to travel with their bicycles. Widespread installation of bicycle racks on buses responds to this small but growing segment of the population of transit users.

GCRTA is a good example of an agency that has committed to facilitating cycletransit coordination, with its rising rate of bicycle-on-bus boardings over the time period of 2008 to 2011. Even as the absolute numbers of annual BoBBs fell over the time period, from about 45,000 to 41,000 , service levels and unlinked passenger trips fell even more, resulting in rising numbers of BoBBs per 1,000 UPTs (from 0.92 to 1.09$)$. 
This research project allows us to answer the question, "What affects the daily systemwide number of bicycle-on-bus boardings?" BoBBs are clearly influenced by weather conditions. If it is cold, rainy, or snowy, fewer BoBBs are recorded. While not surprising, the model confirms what common sense would suggest: warmer and drier days are associated with higher levels of BoBBs. Still, even in the coldest months in northeast Ohio, an average of almost 50 daily BoBBs was recorded. Hardy souls use the bus bicycle racks in fair weather and in foul-intentionally and perhaps sometimes unintentionally when a dry morning trip is followed by a damp return best avoided by taking the bus.

On the other hand, weather does not appear to be a terribly important predictor of general ridership, an interesting and important distinction between the two types of transit users. Though in colder and wetter weather conditions GCRTA sees higher transit ridership - probably because of greater numbers of high school and college students taking transit in cooler months-the strength of the statistical association is not high. This suggests not only that transit riders are undeterred by bad weather (and should probably carry umbrellas and wear warm clothing when the forecast is bad), but that transit shelters are necessities, not simply amenities.

Other factors also influence BoBBs, transit service levels being particularly important. The results of this analysis suggest that bus bicycle racks provide a valuable service to transit riders. For those transit users who would ride the bus even if they could not travel with their bicycles, transit trips may be all the more convenient when racks are installed on buses. For those transit users who would not ride the bus without the bike racks, their presence is even more important, facilitating transit trips that would not have been possible otherwise.

What does not seem to have a large impact on BoBBs is travel cost. Bus fares are positively associated with BoBBs, and the cost of gasoline is as well, though in each case regression analysis reveals the association to be weak. Undoubtedly the prices of bus fare and gasoline influence some rider decisions, including some who travel with their bicycles, but the impacts are not nearly as important as the other factors assessed in these models.

This analysis suggests several very interesting follow-up questions. To what extent do bicycle-friendly transit policies and facilities expand geographic access to public transit? How many CTUs are new transit riders who could not or would not use public transit otherwise? What trip purposes are most important to cycle-transit users? How highly do transit users value the ability to travel with their bicycles, and 
how is that value best measured? And at what systemwide threshold do BoBBs exceed capacity on bus bicycle racks, creating frustration and unmet demand?

This last question concerning the point at which demand exceeds capacity has important implications for transit agencies. At the systemwide level, even on the days of heaviest use, GCRTA has little to worry about, as plenty of excess capacity exists. But systemwide excess capacity does not help the would-be cycle-transit user whose preferred bus already has two bicycles in the front rack. This may already occur frequently on the bus routes that have the highest rates of BoBBs, but we do not know this with certainty.

Still, with rising rates of BoBBs, it is clear that, at some point, either the supply of bus bicycle rack space, demand for it, or both, will need to be addressed. Bicycle racks with the capacity for three bikes could create a larger supply and are already in use in some regions. These could be considered for installation on GCRTA bus routes with the largest numbers of daily BoBBs. Addressing demand could involve the establishment of bike-share programs and the installation of sheltered and secure bicycle parking at stations. In this way, more CTUs could combine bicycles and transit, without having to travel on transit vehicles with their bicycles. Getting to the point where more riders are clamoring for bus bike rack space than is available would be a difficult problem to address, and a good problem to have-a demonstration that the service is valued and needed by a large number of people.

\section{Acknowledgments}

This research project would not have been possible without the assistance of the following staff members of the Greater Cleveland Regional Transit Authority: Joel Freilich, Assistant Director of Service Management; Floun'say R. Caver, Ph.D., Director of Service Quality; Heather Bates, Planner III, Service Management Department; and Kay Sutula, Senior Budget Management Analyst. Appreciation is also due to Richard Heiberger, Professor of Statistics at Temple University; Robert Cervero, Professor of City and Regional Planning at the University of California, Berkeley; and Jacob VanSickle, Executive Director of Bike Cleveland. Finally, the author would like to acknowledge the valuable contributions of two anonymous reviewers for the Journal of Public Transportation. 


\section{References}

APTA. 2011. 2011 Public Transportation Fact Book. Washington, DC: American Public Transportation Association.

Bachand-Marleau, Julie, Jacob Larsen, and Ahmed M. El-Geneidy. 2011. The much anticipated marriage of cycling and transit: But how will it work? Transportation Research Record 2247: 109-117.

Chen, Cynthia, Don Varley, and Jason Chen. 2011. What affects transit ridership? A dynamic analysis involving multiple factors, lags and asymmetric behaviour. Urban Studies 48(9): 1893-1908.

Freilich, Joel. 2011. In person conversation with the author on January 25, 2011, Annual Meeting of the Transportation Research Board, Washington, DC.

Hagelin, Christopher. 2005. A return on investment analysis of bikes-on-bus programs. Tampa, FL: Center for Urban Transportation Research, University of South Florida.

Krizek, Kevin J., Eric Stonebraker, and Seth Tribbey. 2011. Bicycling access and egress to transit: Informing the possibilities. San Jose, CA: Mineta Transportation Institute, San Jose State University.

Krizek, Kevin J., and Eric W. Stonebraker. 2010. Bicycling and transit: A marriage unrealized. Transportation Research Record 2144: 161-167.

Krizek, Kevin J., and Eric W. Stonebraker. 2011. Assessing options to enhance bicycle and transit integration. Transportation Research Record 2217: 162-167.

Lane, Bradley W. 2012. A time-series analysis of gasoline prices and public transportation in U.S. metropolitan areas. Journal of Transport Geography 22: 221-235.

Pucher, John, and Ralph Buehler. 2009. Integrating bicycling and public transport in North America. Journal of Public Transportation 12(3): 79-104.

Schneider, Robert. 2005. Integration of bicycles and transit. Washington, D.C.: Transportation Research Board. "TCRP Synthesis 62" would provide additional helpful information to readers looking to access this publication.

Stover, Victor W., and Edward D. McCormack. 2012. The impact of weather on bus ridership in Pierce County, Washington. Journal of Public Transportation 12(1): 95-110. 
Taylor, Brian D., Douglas Miller, Hiroyuki Iseki, and Camille Fink. 2009. Nature and/ or nurture? Analyzing the determinants of transit ridership across U.S. urbanized areas. Transportation Research Part A: Policy and Practice 43(1): 60-77.

\section{About the Author}

Bradley J. Flamm (bflamm@temple.edu) is an Assistant Professor of Community and Regional Planning at Temple University in Ambler, Pennsylvania, where he conducts research on the environmental and energy impacts of transportation systems, climate change action planning at the municipal level, and sustainability in suburban communities. 